\title{
The Subordination Coalition and Its Effects in the Labor Law Efficacy on the Relationship between Worker and Employer in the Jordanian Legalization
}

\author{
Faisal M. Al- Shogairat ${ }^{1}$, Ibrahim M. Abuhilaleh ${ }^{1}$, Noor T. Bdour ${ }^{2}$ \& Asharf H. Krishan ${ }^{3}$ \\ ${ }^{1}$ Faculty of Economic \& Business Administration, Law Department, AL Hussein bin Talal University, Jordan \\ ${ }^{2}$ Faculty of Educational Sciences, AL Hussein bin Talal University, Jordan \\ ${ }^{3}$ Ministry of Municipal Affairs, Ma'an, Jordan \\ Correspondence: Faisal M. Al- Shogairat, Faculty of Economic \& Business Administration, Law Department, \\ AL Hussein bin Talal University, Jordan. E-mail: dr.faisalshogairat@yahoo.com
}

Received: December 9, 2016

Accepted: December 22, $2016 \quad$ Online Published: June 1, 2017

doi:10.5539/jpl.v10n3p69

URL: https://doi.org/10.5539/jpl.v10n3p69

\begin{abstract}
Labor law has a significant social need that it is organized a category which could be the biggest between the society categories، and it has the obvious effect upon rules which came in most of it in the committed trait to find the minimal limit from the labor laws so it organized their relationship with employer.

Thu, the worker related with employer in contractual relationship, impose controversial duties and laws upon the two parts ' and in order to be in front of contractual relationship that refer to labor law rule, it should has three conditions, which are: (work should be paid, private, and dependency). According to what subordination coalition performs of special importance that represented in the worker situation in a legal position that make him worth the legal protection, this coalition results in worker responds the orders and directions from employers، the employers right in administration and supervising، and the need of worker to respect this right, and what spots the practical execution for the work contract from the worker failure in doing his duties an entering the punishments taboos, and appears a type of works that weak with it the supervising that worker receive it from the employer, in addition to the role of subordination coalition in discrimination the work contract from others similar contracts. This element has been searched and what could be results from it as legal and practical difficulties that imposed legal situations which reflect on worker stabilization in his work.

The ultimate goal of this research is in the investigation the extent of the subordination condition importance in the work relation and its role in implantation the Jordanian labor law rules on that relation.
\end{abstract}

Keywords: administrative dependency, economic dependency, labor contract, legal dependency

\section{Introduction}

Work is considered to be an important social and economic task and a real pillar that enables man to life a decent life, for that reason, it is found since the origin of the universe, when our God ridiculed the land for the man and ordered him to seek for his sustenance ${ }^{(1)}$ and to construct it, therefore the importance of work increased with the succession of civilizations and its evolution. We find that the labor relations were based on a slavery system pursued by the employer (capitalist) towards the workers (the poor class) that caused the weakness of their rights and the inability to claim and accept work according to the conditions dictated by the employers, whatever the Harsh it is. After the uprising of modern civilizations and the industrial revolution in Europe and the observation of the bad working relationship that was unfair and injustice, the labor laws were used to regulate the labor relations and to put an end to the cruelty of the employers who were seeking for gaining the profit and make money without paying attention to the workers and their rights. ${ }^{(2)}$

\footnotetext{
(1) Verse 15 Surah AL molk and verse 39 and 40 An-Najm.

${ }^{(2)}$ For more information see: Dr. Tawfiq Faraj and Wael Bundq, the new Labour Law, third Edition),2007, Ibrahim AL nahel Foundation, Alexandria (page: 49) \& beyond.

Then see also: Dr. Sayed Ramadan, the mediator in explaining the labor law, the House of Culture publication, Oman, 119, page 9.
} 
As for Jordan, the Jordanian constitution 1952 had ensured in Article(2) the workers right to work, and their rights to gain wages and other rights, too. Moreover, the commitment of the state to provide employment opportunities for its citizens, then followed by the Labor Law No.21 of 1960 as a Jordanian social legislation that handles labor issues and provides justice and social peace ${ }^{(3)}$, then followed by The new law No. 8 of 1996 (as amended), for the regulation of labor and workers relations and sets the minimum labor rights, also the Jordanian civil law handles the individual contract in articles (805:832).

Labor relationship on which the rules of the labor law and the other legislations are applied must contain the following conditions; they are: The work should be hired, private, and subordinate.

Because of the importance that we found in the search of the third condition which is that work must be incidental as it is an essential element in the labor relationship, we decided to give attention to that condition and to its provisions in law, jurisprudence, and judgment in Jordan, we started by the definition of work, labor law, and then indicate what the legal subordination its components, its origin, forms, as well as the economic dependence, finally the importance of the dependency element in the distinction between the contract and some contracts that are similar to it, then the search ends with the conclusion. This research was divided into two sections preceded by a preface.

\section{Preface}

\section{The concept of (work):}

Through this research it is found that the definitions and concepts of work has varied, we find that the Jordanian Labor ${ }^{(4)}$ Law define work as: "Every intellectual or physical effort done by a worker for a employee, whether it is permanent or temporary or seasonal, "while we find a difference between the scholars and writers on the state of mind definition and inclusive work their definitions had been distinguished To work, Some of them defined ${ }^{(5)}$ it as:

"Specific activity of distinctive human characteristics and a source of wealth, civilization and the good of man and society, the work is a sacred duty of every capable human being."

While others defined it as ${ }^{(6)}$ "It Is every muscular or intellectual effort from the man enters his so valuable commodity produced or service provided."

From the above we can define work as:

"Every movement and creativity from the man which makes a change or something new for its own or for the others benefit ".

The work will be movement, or mental or intellectual creativity or so by a person changing or earns other forms of things or creating something that did not exist before.

The author, for example, doing an authoring work and prepare composed of mental or intellectual production, and the worker may build a house and the teacher may teach the children, all of that involves a particular action it is difficult to count all business and works.

It must be noted here that the Jordanian labor law does not govern all actions of the human but governs one relationship between business and workers, and where the work performed by the person; as a hired and subordinate employee.

Through the concept of the work contract, we find that the work is governed by the rules of labor law as they always have been accidental and temporary and seasonal ${ }^{(7)}$.

The labor law that governs labor relations some have said ${ }^{(8)}$ that: "It's Legal rules which govern labor relations

(3) See: dr. Jaafar al-Mughrabi, explaining the provisions of the Labor Law, the House of Culture for Publishing and Distribution, Amman 2016 .pp:21-22

(4) Article (2) of the Jordanian Labor Law 8 of 1996, as amended, and found corresponds to Article (29) of the Egyptian labor legislation, known decade as: "is a contract that pledges whereby a factor that works for the employer and under his direction and supervision for a fee".

5 ) dr. Amer Ali, Explained the Jordan labor law, $1^{\text {st }}$ edd, 1999, National centre for publishing, p:5.

${ }^{6}$ ) Ahmad Abo Shnb, Explained the Jordanian's new labor law, $1^{\text {st }}$ Edd. 1998 , p:5

7 ) Returning to the second article of the Jordanian Labor Law found that business had known what was coming:

a- Accidental work: work that is dictated urgent need for a period of not more than three months for completion.

b- Temporary work: work accomplished nature of which requires a limited period.

c- Seasonal Work: Work in specific seasons of each year and not more than six months duration.

${ }^{8}$ ) Dr. Mansour Otoum, explaining the Jordanian labor law, comparative study. Without the year of publication, without the date of 
of subordinate employee, whether individual or collective relations, and organized labor and workers' affairs. " While another defined ${ }^{(9)}$ that:

"Legal rules governing the terms of the relationship arising from the natural person to work for the benefit of another subject of private law and under each a entertained or its management group for a fee."

From the above, we find that labor law is: "the legal rules that govern the work of individual or collective".

\section{"Condition validity of the provision of labor law on the employer \& employee relation"}

The terms of the labor law provisions entry into force and its impact on the relationship of employee and employer:

The special working relationship in light of the provisions of the labor law must be carried out under the worker subordination to the authority and supervision of the employer, which necessitated the law and there are special conditions of work for the entry into force of the rules of this law on the outskirts of the contractual relationship, and the resulting effects, and these conditions are:

\section{1) To be special work:}

Work may be a public which it is not subject to the labor law, on the grounds that the administrative relationship between the parties of the year working relationship represented in the state administrative bodies, public institutions and municipalities on the one hand, the public employee and an employee of the municipal party.

Other and therefore they are not subject to the provisions of the labor law, as the Jordanian legislator has excluded these relations from the provisions of the law. Work does not apply the provisions of their actions and their behavior ${ }^{(10)}$ but subject to the provisions of administrative law and regulations them.

On the other hand, the work is special between two or more people for profit or otherwise, nothing to do with the state or one of its employees. It is the work being done by the person for its own account or for someone from the private sector under the contractual relationship defines the rights and obligations of each party to the contract, and be the rules of labor law and legislation and regulations relating to him alone that apply to this type of relationship, and this work is subject to the provisions of the labor law and the rules of private law relating there to and the parties to the contract to invoke rules.

\section{2) Paid work:}

A wage is constituted a real guarantee for a worker and his family as an element to cope life costs and burdens, as the need to pay sometimes pose real motive for a worker to work under the conditions of harsh conditions, borne to provide a living and pay the wheel of life ahead, and some believe ${ }^{(11)}$ to pay his diet in nature, as a source of livelihood and the only main factor and his family live it often.

This may be the work contract hire earns whereby factor Agra is an amount of money, or rather in kind and subject to the rules of labor law, may be some of the work without pay does not receive a person's wages for those business and financial compensation for his work, which is known volunteer here are governed by the rules of civil law, and therefore pay entitlement for the work is a condition of entry into force of the rules of labor law and other rules of private law, and considering that the employment contract of netting contracts that group would present the work in exchange for remuneration received by the owner. Work as a result of their contract, and work linked causation, each of them another reason to ${ }^{(12)}$.

\section{3) The working relationship of dependency:}

Work on other contracts similar to the presence of dependency element, which apply with the provisions of the work on the relationship factor employer law of contract varies, but dependency may not be the only criterion to undergo this work with the provisions of the law referred to, but there are cases where the employer is a follower however is not subject to the work of the law by law, in our example that municipal employees.

publication, page 8 .

9 )Dr. Jafar Magraby, explaining the provisions for labor law, p: 19.

${ }^{(10)}$ Article (3) (Jordanian labor law, see: dr. Jafar Mughrabi, explain the provisions of the Labor Law, page (27) and (28) See also Dr. Ahmad Abu shanib, explaining the Labour Law, p. 58.

$\left.{ }^{11}\right)$ See dr.Sayed Ramadan, the Mediator in the explanation of the labor law, p: 135.

${ }^{(12)}$ See: Dr. Ahmad abu Shnab, Explained labor law, p: (64-65); Wage - linguistically is the payment for the work ( Al.Fayrouz Abadi), al. Mohet dictionary, the first part, p:362. Whereas legally wage defined as " Every employee deprives for his work in cash or pulls, in Addition all his other duties what ever it's kind, Article (2) from the Jordanian labor law. 
The subordination is defined as: "a relationship during which the worker is subject to the orders of the employer and the supervision and subject to sanctions" ${ }^{(13)}$, so the element of dependency is one of the conditions to be achieved in a relationship worker to the employer, and as a result are subjected to such a relationship with the provisions of the labor law, and given the importance of this relationship amounting to hold work we have studied and determine their types.

\section{The first topic}

\section{What are the legal subordination and its components}

We pointed out that the dependence is one the most important elements of working with the poster of the work item, and to know this element we have to deal with this matter in some detail as follows:

\section{First requirement}

\section{What is the legal subordination?}

Before in-depth search item or a relationship of dependency as a condition for the entry into force of the rules of labor law on the employee relationship with employer work, we find that it is necessary to define the work contract.

Employer relationship with his employees, and overall factor associated with the contract is the first source of commitment, one of the most important of these sources, and is a contract the most prominent part of the rules that govern commitment ${ }^{(14) \text {. }}$

The decade as one of the most important sources of commitment is: "An offer from one of the other contractors and acceptance of its impact on meeting him and consequent commitment to each other as committed to him for another" ${ }^{(15)}$.

Returning to the Jordanian labor law, we find that Article 2 of the known employment contract as "a verbal or written agreement explicitly or implicitly undertakes under which to work for the employer under his supervision and his administration for a fee and a labor contract for a limited period, or unlimited or for a specific action or non-specific.".

We also find that the legislator define the work contract in Article (805) of the Jordanian Civil Code, which came out: " that is A contract in which one part is committed to doing the other for the benefit of under his supervision and his administration for a fee."

The definition of idiosyncratic labor contract some it was defined as ${ }^{(16)}$ :

"Contract in which a contractor undertakes to work in the other Contracting Service and under his administration and supervision in return for remuneration vows by the other contractor."

And also there along with Shariah scholars and they explain the subordination of the employer element through its definition of the employment contract as "a contract which is committed to the development of his labor power at the disposal of the employer for a specified period or an unspecified monetary reward in exchange for or in kind to accomplish a particular job or not certain under the management and supervision of the latter and directing "(17).

It is legal and jurisprudential concepts set forth in the preceding paragraphs clearly highlights the coupling element or the Association of Streptococcus dependency relationship between the worker and the employer, so it can not be applied to work on the legal relationship law element does not have dependency representing management or supervision and guidance by a substantial component.

It is noteworthy that the jurisprudence has settled on the most important characteristic of the work for other trade contracts held is legal dependency element ${ }^{(18)}$ and called this label because they arise from contractual

\footnotetext{
${ }^{(13)}$ See: Dr.mansour Otoum, explaining the Jordanian labor law, Page 8

${ }^{14}$ ) For more see: Adnan Sarhan and Nuri al-Khater, explaining the Civil Code ( sources of personal rights: Obligations) comparative study, the first edition, the second version, the House of Culture for Publishing and Distribution, Amman 2005, page 114

${ }^{(15)}$ Article (87) of the Jordanian Civil Law (43) of (1976).

(16) Dr. Abdl Razek Al Sanhouri, The mediator in the explanation of the new civil code, part 1, contracts set to work, Dar-al Halabi publication, Beirut, 2000, p:13.

${ }^{(17)}$ Doctor. Khalifa Abdel Moneim, the individual employment contract, the first edition, the National Center for versions, Cairo 2008 Page 17.

(18) We conclude that the decision of the Court of Jordanian discrimination in one of its provisions number) 206/95 that brought him: "The establishment of worker organizing computational work with the employer without being restricted to a certain time and without supervision
} 
Association underlying perform work for the employer, and follow the employer ${ }^{(19)}$, The Jordanian legislator taking this thing when Known factor in Article (2) of the Labor Act, saying: "Every person is male or female, who performs work for a fee and be a follower of the employer and under his command includes juveniles and under training or prequalification.

Here is a work dependency relationship between the worker and the employer as a result of the employment contract, and the absence of such a relationship, or item dependency factor for the employer requires that the labor provisions in the law does not apply in this case is heading legal qualification of the contract as a contract of another kind, according to the decision of the Court of Cassation referred to, which stressed that the person arithmetic operations to last for an indefinite period and without the supervision of makes this contract and applies the civil law and the laws and regulations on the other.

The Jordanian Court of Cassation in its resolution No.64/392 decided:

"That the employer oversees the workers when his dominance on the activity of the Group during the execution of the contract, and control his working methods and its borders, and hold him accountable for his work and that the project is device management, it is not necessary to provide a corner oversight to trace the employer working constantly and is doing his job" ${ }^{\prime 20}$.

An analysis of the Court of Cassation's decision contained above is clear to us that the dependency element achieved two conditions, namely; the legitimacy of the employer in the guidance and issue instructions on the implementation of worker for his work, and the authority of the employer in the accountability factor when failure to implement those instructions.

We find that some element of legal dependency define ${ }^{(21)}$ "The factor that work under the authority and supervision and guidance of the employer who is entitled to direct orders to the worker and monitor the implementation of those orders and sanctions in case of violation."

These legal dependency often accompanied by economic dependency or financial remuneration is derived by a worker from the employer element, which makes the worker continued to employer in economic terms, as we shall explain later.

The concept of subsidiary as former mean in the case of absence it is not possible to work on the application evolving relationship law between the employer and the worker, as well as nullify this dependency that the worker is doing his job independent of the same account no longer working relationship, and then the provisions of the labor law does not apply to the lack of liability for the employer or the supervision of it.

Examples of private Business: The work of doctors, lawyers, pharmacists and teachers in private schools, all of them are paid remuneration for work without linking them to the employer with any dependency relationship and they are not under the control or supervision of doing the work for its own account, which makes them independent in front of the latter in spite of they are paid wages in exchange for this work, and their work is independent act is not subject to the rules of labor law but subject other laws ${ }^{(22)}$.

\section{The second requirement}

\section{Occurrence of dependency relationship}

Subordination make the worker in the legal status makes it imperative to protect the legal provisions, and as this center that he would need for such protection because of the social and economic importance of the work for this worker $^{(23)}$, this is taken element of dependency as a condition of the application of the provisions of labor to work between the worker and employer relationship law. Whether the worker is subject to economic dependency when the worker based in which the wage as the only source of livelihood, first be subject, as have other sources of income, as well as whether the employer accounts for the work factor, or was it last worked for other business owners at the same time and the availability of this component and accessory Association this does not mean monopoly employer and if sometimes economic dependency did not materialize and labor law applies even

by the employer, makes the contract and not a contract of employment.", Published on page 2393 Ninth Issue 37 Journal of the Jordanian Bar Association.

${ }^{(19)}$ Dr. Tawfiq Faraj and Wael Bondk, the new labor law, page 114 and beyond.

${ }^{(20)}$ See: Jordanian Bar Association Journal in 1965, Page 188.

(21) See: Dr. Amer Mohammed Ali, explained the Jordanian labor law, Page 19.

${ }^{(22)}$ See: Dr. Sayed Ramadan, the mediator in explaining the labor law, Page 129.

${ }^{(23)}$ See: Dr. Abdul Wahid Karam, labor law, the House of Culture for distribution and publishing, Amman, 1998, page 9 and beyond and see: Dr. Ghaleb. Daoudi, the explanation of Jordanian labor law to explain; comparative study, " first Edd. serine Press, Irbid 1999, page 8-9. 
though the dependency achieved. Legal For example, someone working with the employer unrequited then we are here in front of the case of a donation and to hold action, rules of civil law rules not labor law ${ }^{(24)}$.

We find that the employee will receive the money in exchange for undergoing the administration and supervision of subordination in order to be able to pay basic expenses.

From the above, we find that the dependency element is based on three pillars namely" in details:

\section{First: the employee's service the employer and therefore, the employee will not be a partner to the} employer:

One element components of dependency need the service to the employer. This means that an employee for someone else works and become an affiliate his work under his administration it includes reported second article of the law, such as teenagers and workers under training or vocational rehabilitation.

A worker who performs his mission in favor of the employer in accordance with the contractual relationship and being paid, and thus, this node is not a holding company or a donation.

Accordingly, the case of the doctor or tutor or lawyer and doctor do not have a dependency relationship to the lack of an employer is a recipe for an independent employee.

During the validity of the employment relationship, the employee needs counseling as the guidance process is an important part of the administrative process that focuses on the human component in the company's paint a sound steps to fit him for work This includes the need to direct the employer and the employee to complete the cooperation between them and the rest of the staff and motivate the system to work in their ultimate potentials ${ }^{(25)}$ so that reflected on the success of the company and access to the level of a reasonable profit while preserving the interests of the various employee. It should coincide with the presence of the authority of the employer to be able to activate these important elements with control them and their workers to hold negligent, according to contract.

\section{Second: undergo worker to the authority of the employer:}

Where unique employer administration may be involved with one of the employees in this process, or a representative of the workers, it represented this administration and supervision in determining the times of work and according to precise schedules and not to work for others during the same time and in this case it is important to have set the time according to the contract between them or unilateral decision of the employer ${ }^{(26)}$ and then the power that is available to the employer is one of the basic components to create a dependency element and the employer is entitled to issue directives and the application of sanctions in case of violation of decisions and if the employer is not missed the presence of the element of dependency.

There is no requirement for the application of the control authority of the employer and employee in one place exists, but power may exist despite the spatial dimension between the parties to the contract. It is enough -as we see- worker to be under the authority of employer and followed his directions and instructions, also undergoes to his sanction.

\section{Third: it undergoes an employee to oversee the employer.}

For there must be undergo a prerequisite for the supervision and guidance employer, where he owns the real power in the direction and control of the implementation of orders ${ }^{(27)}$ This is a prerequisite in addition to the previous conditions to complete the employee subordination to the employer system and thus employer is entitled to monitor the implementation of the employee for his work may be directly or directly by supervisors. Undergo the process may be weak for the benefit of working example, the case of a doctor who works at the hospital where he has the right to work freely and that examines cases of patients at the discretion and not in accordance with the instructions of the Director or employer. At the same time, the doctor who treated patients at a private clinic is not subject to the provisions of law, the absence of a dependency element while as the patient undergoes to the doctor's directions. But the doctor, who works employee at a government hospital is subject to the Civil Service Act, a contractual relationship with a special nature ${ }^{(28)}$ and when the contract doctor or lawyer with the employer in this case could be considered employees if with reasonable elements, such as the existence

\footnotetext{
(24) See: Dr. Amer Muhammad Ali, explained the Jordanian labor law, page 20.

25 ) For more: see modern management concepts, dr. Omaima Aldhana et al., Edition 12, 2014, books Jordanian Center, Amman, Page 187 \& beyond.

(26) See: Dr. Sayed Ramadan, the mediator in explaining the labor law, Page 131.

(27) See: Dr. Abdul Qadir Al Far, sources commitment, the House of Culture for Publishing and Distribution, Amman, 2011, p. 215, Nedal Grada, dependence on individual labor relations, p. 58.

28 ) See Dr.Amer Mohmad Ali, explained the Jordanian labor law, p:22.
} 
of administrative subordination or regulatory ${ }^{(29)}$.

The doctor or lawyer or university professors undergo to a reliable work list by employer by employer and commit in his work and this is an evidence for absence of dependency element.

Jordan discrimination Court confirmed the order by resolution 1231/97: (If the prosecutor is working part-time lecturer at the Prosecutor Foundation According to the contract between them, it does not fall within the faculty members within Article II of the list of teaching at the University of Jordan body and therefore it is not within the university staff $^{(30)}$.

From the above, we find that the need for the employee under the supervision and guidance of the employer directly or indirectly working example of what is happening in some parts of Japan, where the distribution of audio-visual equipment houses and each person perform the work of its part in the home as required sequence (31).

As a result of technical tremendous development and the spread of e-commerce several new relationships to work emerged, such as trade after work or a salesperson via the Internet, according to a contract or agreement of paid and this in turn weakens the control and supervision element and be lost as a result of his dependency system has been an employee exceeds some special work assignments in the absence of establishment or one place that combines the employee and the employer so it should be a huddle employer with all the mechanisms and means to ensure his control and monitoring the activity of its staff.

According to the last case which may create a difficulties in observation from employer, we find that employer should organize the work between him and the employee in which employer control on contract execution and employee observation during the execution, conditionally enable the employee with employer's equipment and networks with websites passwords or program that make employee undergo employer authority and under his observation even if they are not in the same place.

We should note here that the employment contract remain valid and continue dependency Association and supervision regardless of the ${ }^{(32)}$ for changing the employer because of the sale of the project or merge the company or inherited, and here we find that the law could save the employee's rights in the case of changing the employer for a period of six months after the change the employer unless the employer with a personal consideration in the contract. In addition, the death of the employer doesn't end the employee contract, except if it's personal ${ }^{(33)}$.

\section{The second topic}

\section{The availability of legal subordination and its Types}

Association of dependency arise once the employment contract where the employee puts himself under the authority of the employer and the subordination of two types and must be the presence of elements or constituents illustrate this dependency legally directly enhancing the legal relation between the employer and employee, also we find from the work contract of execution has many types for legal dependency correlation which increase according to each types, thus we will discuses it in the following:

\section{First requirement}

\section{Check the legal dependency element in the practical side}

It may be an employment contract for a specified period or non-specific, and the consequences for the contract deal directly or indirectly between the two parties and this requires the supervision of the employer for the duration of the contract and indicates that supervision within the legal elements of dependency, but what is meant by extension? And how they arise? And how to become part of the basic components of the employment contract?

In view of the provisions of the Jordanian law, the element of subordination available by supervisor on employer's workers during the execution of the contract search determines his steps to the project without of

\footnotetext{
29) See: Alkadhia Hussein Hamdan, the Lebanese Labor Law "comparative study", al-Halabi legal publications, Beirut. Version 3, 2007,p:1999 \& beyond.

(30) Judicial Journal / Judicial Institute of Jordan, First Issue Volume I, July 1997, page 394.

${ }^{(31)}$ Back to Amer Muhammad Ali, explaining the Jordanian Labor Law, p. 23.

${ }^{(32)}$ Article 16 of the Jordanian labor law.

${ }^{(33)}$ Article -22 of the Labor Code of: "the employment contract does not end because of the death of the employer, unless taken into account in the personality of the employer contract".
} 
observation to follow the employer continuously during working ${ }^{(34)}$.

It's clear to us through this definition that the dependency element is achieved through two conditions, namely the validity of the employer to issue instructions and authority in the employee's account that was not implemented these instructions ${ }^{(35)}$.

Accordingly, the supervision of the employee during the execution of his work and the implementation of the sanctions on the employee of the most important elements of the legal subordination. It is important that there is a real supervision authority of the employer, whether temporary or seasonal work, and the worker is not a natural person and a legal person ${ }^{(36)}$ and the Association of subordination of the most important advantages of working Association and Article (805/1) Jordanian civil law describes this element and Article (2) as well as the work of a Jordanian law also It is clear that the dependency related to that employer has supervisory authority or management employee and the right to issue directives and employee adhere to these directives, but offer the same legal penalty ${ }^{(37)}$.

Here's a question whether the employer's authority in the employee's personal authority directing Is it permissible to hire this power to others?

The employer may direct the work the work by himself or to others mangers given them some of this authorities, and to have two legal positions in the same time, and we find that the Jordanian legislator also the judgment take the large concept for the legal dependency without the absence of technical dependency, the legal dependency is enough. The employers role is to specify the work conditions as the type of work, it's time, it's place without the work essence, all of this types without disruption of the employer authority by doing the sanctions in the judgment ${ }^{(38)}$.

The legal subordination practically from the employer in terms of supervision or management work as well as the power to enforce sanctions on violators .

We should differentiate between management and supervision determining working conditions such as working hours and holidays, and this consider as one type of legal dependency types which we will discuses later, The administration relates could be moment by moment for all the details of the action minute observation was carried out by agents of the employer and could be indirect that that the employer give work to others agents to observe employee with records or reports.

The non-legal relationship between the employee and the employer, such as contracting with a foreign employee are no procedures contrary to law. Article 12, paragraph (a) of the Labor Law and the Jordanian remember the following:

(It is not use any non-Jordanian worker only after the approval of the minister or deputy minister and that this work is a requirement for the experience or the lack of a sufficient number of national manpower to accomplish) and it must be non-Jordanian worker to obtain permission from the Minister of Labor ${ }^{(39)}$.

But Jordanian Court of Cassation made the labor contract without a permit valid contract and said:

(Where the labor contract according to the law is a verbal or written agreement or tacit perform work for the employer for a specified period or non-specific and pay a fee).

The benefit from that is the employee do the work for a wage and for employer dependency, and the saying that foreign workers doesn't have a permission that make wrong work contract that no annulment without a legal text, that work contract has been met the conditions which is demands by the law ( labor and wage, and the relation of dependency), so that if the employer doesn't get a work permission from the specialist parties, according to

\footnotetext{
(34) Decision of the Court of Cassation 392/64, published in the Journal of the Bar Association 1965/188.

${ }^{(35)}$ See: Dr.hisham Hashim, explaining the Jordanian labor law, Page 44

(36) See: Dr. Jalal Adwe, labor law, Association of knowledge, Alexandria, 1968 Page 96 and Nedal Grada, dependence on individual labor relations, p. 55

${ }^{(37)}$ See:.Ahmad Abu Shanib, explained Jordan's new labor law, pp. 67-68

${ }^{(38)}$ See: Dr. Amer Mohammed Ali, explaining the Jordanian Labor Law Page 21-23

(39) This is what the court said the Jordanian discrimination in its resolution No. 904/2007 25/9/2007 Where said: "The work that needs to be non-Jordanian Employee of official documents and documents obtained as per the provisions Almadh` 12 Jordanian Labor Law No. 8 of 1996, as amended, and is the synthesis of this statement such as forgery of official documents contained in articles 265262260 permit Penal Code. someone found from the comparative jurisprudence that inference elements on legal dependency should be with following : instructions that employee undergo it, have sanction \& punishment if he doesn't work, his committed in work officinal times his commitment, employee right in his salary daily, weekly or monthly . see Al Qadi- Hussein Hamadan, Lebanese work, comparative study , p: 197.
} 
Article (2) of the law , that doesn't invalidate the contract and doesn't effect on workers rights given by law , thus responsibility to have employee work permission is on the employer ; work permission is because foreign workers organization to Jordan" ${ }^{(40)}$

The relation of dependency has been interrupted or finished depends in some cases, such as the freezing of the employment contract, here as the incidental or personal relations in external work environment, as employee do something wrong that nor related to work, and here employer has no right to punish employee, the employer may punish an employee shall not be conducive employee secrets work so that the finished work times to others

Although many authorities employer in management or observation and after punishment till the end of the work contract, but the employee or worker obtain protection of the law is not entitled to waive his rights ${ }^{(41)}$ so that the owner was forced to work on it, which is not entitled to the employer as well as termination of the contract of the will of a single part, without the desire factor ${ }^{(42)}$.

The employee must be committed to his duties in terms of goodwill, such as not to work for the benefit of others during his official license because it violates the principle of good faith, in this aspect, the employee that get a vacations his right in labor law, he has not to work to anther employer that is violation for his good willing that impose dependency relationship that made a new dependency relationship that not related to legal provisions relationship with employer that give him this vacation ${ }^{(43)}$ that is employee termination for his commitment to work contract.

\section{The second requirement}

\section{Legal dependency type}

Multiple images of legal subordination to another employee and varied love of work, type and circumstances, may be as strong as the technical dependency may be weak, such as administrative subordination ${ }^{(44),}$ thus the types of the legal dependency are technical, administrative and vocational subordination as the following:

\section{1) Technical subordination}

It is subject to the employee directly orders to the employer in all the fundamental particles work or essential ${ }^{(45)}$ and in the case of direct and strict supervision of the employer at every moment, and within minutes the action plan and all in all work details that the employer draw the work plan ${ }^{(46)}$.

This includes knowledge of the employer to know the full details of each work that is done according to the instructions and its own orders.

The technical subordination is considered the strongest types of legal dependency that assume that this case of direct contact between the worker and the employer at every moment and partial and that employer is specialized at work type and mange, direct the employee ${ }^{(47)}$.

$\left({ }^{40}\right)$ Rights discrimination Resolution No. 3705/2004 (General Authority) 20/2/2005 publications Justice Center.

${ }^{(41)}$ For example: According to paragraph (b) of Article 4 of the Jordanian labor law "shall be void every clause in the contract or agreement, whether concluded before this law or after abdicate under which any worker for any of the rights granted him by this law," and promotes this text lots of court rulings, such as the decision of the Jordanian discrimination Court rights (No. 3094/2004 issued on 15/ 2/2005 and the decision of the Court of Cassation rights (No. 93/2002 20/1/2002 and the decision of court discrimination rights No: 61/2003 in 14/1/2004. As well as the decision of the Court of Cassation) rights (No. 61/2003 14/1/2004).

${ }^{(42)}$ For more on this topic see: Haitham Almassaroh, Picker in explaining the labor law, the first edition, Dar Al-Hamed for Publishing and Distribution, Amman, 2008,p:269 Judge Mohammed Fendi, the legal and factual justification for the termination of the will of individual contract according to the Labor Law, "Comparative Study. The first edition, Dar Al-Hamed for Publishing and Distribution, Amman 2015 Page19.

$\left({ }^{43}\right)$ See: Dr. Bashar Malkawi, search " the principles of legality in the labor contract in the Jordanian labor law , published in the journal of studies, the university of Jordan, Vol .30, Sharia and law science, issue 2, November , 2003, p: 395.

$\left({ }^{44}\right)$ See: Judge Hussein Hamadan, labor law, p: 198.

${ }^{(45)}$ See: Dr. Side Ramadan, the mediator in the explanation of the Labor Law, p. 132, see also: Mamdouh Mohammed Mabrouk, dependency within the scope of individual work, "an analytical study of the Egyptian labor law and the French relationship," Arab Renaissance Publishing House Cairo

.2009, page 39 .

(46) See: Nadhal Gamal Grada dependency in the labor relations analytical study compared/ Master 2013, Gaza Al-Azhar University: 42-43, see also Mamdouh Mohammed Mabrouk, dependency within the scope of the individual employment relationship, p. 39.

${ }^{(47)}$ See: Mohammed Sharif Abdul Rahman, the pillars of the employment contract, Dar Arab renaissance, initial edition Cairo Page 212,2008. See also: dr .Said Ramadan, the mediator in explaining the labor law, Page 132.

48) See: Hisham Hasham, explaining the Jordanian labor law , $2^{\text {nd }}$ Edd. P: 48 . Nedal Jardy , dependency on individual labor relation , p:43 and beyond ;Mamdoh Mabrock, dependency with the scope of individual work, page 41. 
And criticism prompt technical dependency that it assume the employer is expert in all work details where it is difficult to apply in the case of major institutions ${ }^{(48)}$.

Thus we doesn't find problem in the employee technical dependency on the employer unless others dependency types of economic or legal dependency is found ${ }^{(49) .}$

\section{2) Organizational and administrative dependency:}

We can define the boil employer authority in determining the terms and conditions of work, such as breaks and holidays and working hours .

And that the manager and the employer determines the place done, duration and quality ${ }^{(50)}$ and inspection of workers and ensure that work is done all the time and back to the Jordanian judgment provision we find that: "The court decided that Jordanian discrimination dependency element featured as standard so decides in her decision $^{(51)}$.

'It is agreed in the doctrine and the judiciary that any business depends on two things first employee subordination of the employer and the second for the employee to be paid and that the dependency means submission and work according to the supervision and management of the employer and this does not mean that employer follow the employee all the time and while he is doing work.

Hence, we find that the judicial ruling expanded the scope of legal subordination where added to the technical element of dependency, as well as regulatory and administrative worker and not to work for the benefit of another person or party is committed, otherwise the contract ending or decrease wage accordion to his dereliction (52).

This relationship extends even after the expiry of the work with respect to labor secrets and non-disclosure of information and data employer ${ }^{(53)}$ and even after the death of the employer that his character's role in the company, thus, we find that the legal dependency types comes in the second rank after the technical dependency, it 's important to indicate that the discrimination court decision doesn't take on the technical dependency and assured that we are in front of legal dependency in presence of administrative or organization dependency even with absence of technical dependency, especially in that work that done away of employer as that employee contract with employer to sell goods by network without employee technical's skills, that employee services the goods prices, nature of work and its credits hours, wage from employer ${ }^{(54)}$.

\section{3) Vocational dependencies}

This type of dependency achieve when practicing surveillance on employees with power of attorney from the employer and this is unusual in big companies ${ }^{(55)}$ and the distribution of competence.

I have recognized this formula some interpreters of the law because it is a form of legal subordination and some scholars say that the professional subordination is not independent of the previous forms and therefore, the professional ownership is a form of technical and organizational dependency ${ }^{(56)}$.

This dependency doesn't occur by agreement whereas the employee do it by what laws imposed of obey duty , usually this type is found in the government officer that respect and obey his country and its rules, we doesn't find that work contract includes this type of dependency, that legal dependency is create between employee and employer because of contract either organization and legal dependency has its own content that differ from

\footnotetext{
${ }^{(49)}$ We find that the Egyptian Supreme Administrative Court has ruled in its judgment No. 225 43-year judicial history 18.03.1978, it came in this provision:

"The technical independence in the performance of work do not contradict with the dependency check, as long as the doctor is subject to the functioning of the specific dates of the work to know the employer, and the same would not be exposed to direct teachers to the educational process in an independent manner technically as long as Was subject to the supervision of the organization ", he pointed to this struggle of the judgment J Grada, dependence on individual labor relations, Page 45.

${ }^{(50)}$ See: Dr. Ahmed Abu Shanb, Jordanian labor law, Page 69.

(51) The decision of the Court of Jordan, No 123/87, published discrimination in the Journal of the Jordanian Bar Association, 1990 Page 30.

${ }^{(52)}$ Article (816) Jordanian civil law.

${ }^{(53)}$ Article 818 , " Jordanian Civil Code " and paragraph (b) of Article 22 of the Jordanian labor law

${ }^{(54)}$ Article (22), (Jordanian labor law).

${ }^{(55)}$ See:.Hisham Hashim, the Jordanian labor law explain, 48-49

${ }^{(56)}$ See: Dr. Ramadan, the mediator in explaining the Jordanian Labor Law, p. 133. See also: d. Jaafar al-Mughrabi, explain the provisions of the law. Work, Page 29
} 
others.

There is the case of work at home in favor of the employer via the Internet and moving side of the jurists to distinguish between legal and regulatory dependency, which is not arising out of an agreement between the dependent and followed by the stems from the duty of obedience law ${ }^{(57)}$.

In conclusion, the Law Association is one of the most important relationships that should be maintained in employer and employee relation in special labor laws such as the Civil Code.

\section{The third topic of economic dependency}

\section{Economic dependency}

The employment contract is netting of contracts where each party receives in return instead of what he is doing and is committed ${ }^{(58)}$.

The employment contract is considered one of the netting contracts, where the contractor takes a return against what he offers, the worker will comply with the implementation of the action in favor of the employer in exchange for the latter's commitment to pay the wages, bonuses and any financial implications relating to this remuneration.

The wage whatever the nature of it is the most important rights which the worker is entitled to meet with his work for the benefit of the employer, depends upon this factor in bridging the needs and requirements of his family, it is the source of this economic dependency between the worker and the employer and this dependency realized by adopting an economic factor on the wage, which obtained him for work performed by this accreditation is achieved first, the availability of components; monopoly of employer-based work actively work (worker) and the second; the adoption of the operator (worker) on his wages as a supplier or a single essential to his livelihood and that they know the economic dependency:

"Takeover of the employer-based services work (worker) so that it has done to its supplier is the only means of livelihood" ${ }^{(59)}$.

Perhaps the most important characteristic of wage protection of the rules of labor law for this element as representing the real motive that drives people to work and their quest for money, leading to the need to link the application of rules of protection of labor law physical and social conditions of the workers, and thus protection extends depending on economic dependency to the people in need of that actually protection ${ }^{(60)}$, this thing leads to the result to expand the application of the provisions of the labor law department in excess of a slice of beneficiaries of protection by the law.

Some find that the concept of economic dependency built on the monopoly of the employer on the activity and the efforts of the world, and the adoption of the latter on the cash equivalent of his single-source or head for a living, and then it does not matter that enjoys a factor of independence in the performance of work or not ${ }^{(61)}$.

Another Approach of the jurisprudence saw that the legal dependency enough alone to active the work contract, whether beside its economic dependence or that are not available on most correct opinion, and notes on the contrary, with some going on to say that the economic dependency suffice to say that the existence of an employment contract, even if the legal subordination is not available ${ }^{(62)}$.

This will unite the economic side of the dependency between those independent workers in the performance of their business, and those who are not independent in the performance of those acts. If those in the first group are not subject to management or supervision of the employer, we find that others are in the second group are subject to management or supervision of the owner work, but the officer who brings them together is the economic situation, and this makes them stand at the same distance from the legal protection by the law for a class of workers ${ }^{(63)}$

In turn, we find that the introduction of the Association of economic dependency is not enough alone to do under

\footnotetext{
(57) See: Hisham Hashim, explaining the Jordanian Labor Law, (p. 47-48)

${ }^{(58)}$ Pay is: "Everything deserves factor for his work in cash or in kind plus all the other benefits you, a kind if the text of the law or the rules of procedure or work contract or settled on the deal except to pay wages owed for overtime." Article 2 of the Law Jordanian labor.

$\left({ }^{59}\right)$ See : Ahmad Abu Shnab, the new Jordanian labor law explain, page 68.

$\left({ }^{60}\right)$ See : Hamadi Abdel Rahman \&Mohammad Yahya Matar, labor law, university house, 1987, page 57.

$\left({ }^{61}\right)$ See Hosam Eddin Ahwani, labor law , page 131

( ${ }^{62}$ ) See: Sayed Ramadan, the Mediator in explanation of labor law, page 129

$\left({ }^{63}\right)$ See: Nedal Jamal Jardy , Dependency on labor relation , page 29.
} 
the provisions of the labor law and other rules of private law relevant to the labor contract, because we will make factor as the machine, while we find that the combination of dependency Economic Association of Legal those relating to management or supervision would make a worker at the Center legal best position to enjoy the legal protections imposed by the legislature on the parties to the employment contract, and that the introduction of economic dependency as based on an external element is the economic and social status of the worker, leads to a difference in the conditioning contract for other legal ties are seen at times that a contract of employment and the holding of a contractor or other another time ${ }^{(64)}$, as many of the relationships between individuals have a fee may be sole livelihood for these individuals.

In summary, the legal subordination of management or supervision and guidance are the basis for the application of business rules on the legal relationship that develops between the worker and the labor law which is so attitude is being taken by the Jordanian legislator when he knew the work contract and rely on legal subordination as a basis for the application of the provisions of the law on the work of relationship worker and the employer, which is the same position taken by some Jordanian jurisprudence ${ }^{(65)}$.

We would add that we can not ignore the role of dependency Association as one of the elements of the employment contract in the distinction between contract work and for other contracts and review the facilitator for some of these contracts will realize the role of this association in achieving this distinction and thus can be the presence or absence of this element to adjust the contract that we have with If a contract of employment or other and show, for example, the role of the dependency element in the distinction between contract work and contract on the one hand and holding the agency on the other.

\section{-The employment contract and the contract of entrepreneurship:}

It's known from Article 780 of the Jordanian civil law contract held that "holding one end vows to make something or performs work for the meeting instead of vows by the other party".

The labor contract has been defined by Article 805 of the Jordanian civil law as" A terminal holding that the work for the benefit of others under his supervision departments or for a fee".

We note through these definitions that contract including that one Party will do the implementation work of the other in favor, for a fee, but differ in that the employment contract includes that the worker to the implementation of the work under the supervision and management of the employer without that being in the construction contracts and this is what came in Jordan discrimination Court decision No. 2950/99, "the focus of the distinction between the employment contract and the contract of entrepreneurship lies in the existence of the Association of subordination between the employer and the worker if the defendant works for the defendant and others and has workers pay their wages is contractor and not a worker" ${ }^{(66) .}$

\section{-Employment contract and agency contract:}

Article defined (833) of the Jordanian Civil Code, the agency held that": Contract whereby the client resides another shrine itself at the disposal of legal persons unknown". The notice, despite the similarity between the two contracts in terms of the agent or factor specific work for the benefit of another person for a fee, but the legal dependency element that distinguishes the two decades since it exists in the contract of employment without the agency contract.

Perhaps the overlap between the two contracts that the agent in the agency contract linking dependency relationship with proxy, where summed dependency in the receiving agent orders and directives of the client, and the duty to provide account on the progress of his work, and this may lead to confusion between the agent dependency and dependency factor, but the agent dependency not be class where the worker dependency, given the enjoyment agent deal of independence and authority of appreciation for the client, as long as it works within the agency without the machine in the non-service, legal under any situation is the will, in essence, that's what sets it apart from mere physical work as in the contract of employment, and this is what explains considered the relationship between some of the companies and their workers working relationship, despite the fact that these legal acts, and add that dependency relationship in a deeper work in the agency contract being based on the instructions and orders and specific guidance fruitful version in the worker's behavior in the organization of work and activity and subsequent out of control over the work during the implementation of the action ${ }^{(67)}$, which is

$\left({ }^{64}\right)$ See : Nedal Jarady, dependency on labor relation, page 30 .

$\left({ }^{65}\right)$ Dr. Jafar Magrby, explain the provisions of labor law, page 29.

${ }^{(66)}$ Jordanian lawyer bar journal. vol. $9 \& 10$, September, October, 2002, page 2188.

${ }^{(67)}$ Dr. Tawfiaq Faraj and Wael Bundq, the new labor law, page $139 \&$ beyond. 
what we're missing a lot in the proxy relationship.In addition to the foregoing, the legal subordination has an outstanding importance in determining the distinction between rent contract the company contract and a lot of other contracts work and in determining the scope applied to the emerging legal relationship between individuals of law under such contracts, as well as the element of legal subordination crucial being put worker under the employer's authority and make it comply with the orders that are related to the completion of the work with the note that this power in exchange for not carrying factor of any of the economic risks of the activity, as well as this authority explain the legal protection that is surrounded by the worker ${ }^{(68) \text {, }}$ once it is subject to the authority of the employer of management or supervision

\section{Conclusion}

After that we have to consider the impact of dependency link on the application of the provisions of the labor law and the relationship of the employer to the employee because they are conditions that should be met in addition to the conditions of work should be paid, and should be special, we find that the dependency relation with its types ; the legal part which represents by management, supervision and direction carried out by the employer, and the economic part that related to remuneration as this is the real and the main motivation for worker even with hard work condition. We found the element of dependency plays an important role in distinguishing the work contract for the rest of the other similar contracts, as entrepreneurship and agency, as well as determine the nature of the legal rules that apply to that relationship of presence or absence of this association, and there may be a kind of ambiguity in works or relations done by some persons that make dependency either increase or decrease and therefore certain types of work contracts from this legal list are excluded, What matters that labor law with its social rules came in order in most of it, provide the special legal protection for labor class which describe the most in Jordan, and need the support and assistant and provision of minimum security limit in work, and limit the employer authority with maintaining their minimal limits of their rights. And saying of directed by contract relation from the application will deprived this layer of protection, consequently lack of security and stability at work, thus we found that dependency relation with the importance effect positively or negatively of employees right and security, as we concluded that economic dependency doesn't enough alone to consider the work undergo to labor law provision and others related to special law rules because we make the employee as a machine working under any condition for wage sake without any role of work nature conditions discussion. We should prevent that by accompanied of economic dependency with that legal base related to administration and supervisions which make employee in powerful legal position, and having the legal protection that imposed by legislator for both work contract parties.

\section{Recommendations}

1) The need to amend the provisions of the Jordanian labor law to include the regulation of legal relations between the employer and workers that not gathering in one place, especially in the distance technology business.

2) The need to link the rules of labor legislation and legislation governing electronic protection to maintain the confidentiality of the work and information related to the employer and to facilitate the work procedures.

3) The need for legislative texts soften the harshness of employers and the conditions that put them through the authority of the administration and mitigation for workers because they are the weaker party because it is in need of work and the provision of remuneration, which provides to them and their families a good life.

\section{References}

Abadi, F. (n.d.). AL Mohet Dictionary, the first part.

Abdel-Rahman, H., \& Matar, M. Y. (1987). Labour Law. University House.

Abdel-Rahman, M. S. (2008). the pillars of the employment contract (1st ed.). Arab Renaissance Publishing House, Cairo.

Adwe, J. (1968). labor law, facility knowledge. Alexandria.

Ahwani, H. E. (1991). labor law, without a publishing house.

Aldhana, O. et al. (2014). Modern management concepts (12th ed.). Jordanian books Center, Amman.

Ali, A. (1999). explained the Jordanian labor law, the first edition, the National Center for Publishing .1999.

$\left({ }^{68}\right)$ See: Dr. Sayed Ramadan, the Mediator in the explanation of the labor law, page 133. 
Almassaroh, H. (2008). Picker in explaining the labor law (1st ed.). the Dar Al-Hamed for Publishing and Distribution, Amman.

Daoudi, G. (1999). the Jordanian labor law explained, "A Comparative Study" (1 $1^{\text {st }}$ ed.). Sirin Press. Irbid.

Egyptian labor law.

Faraj, T. H., \& Bundq, W. (n.d.). the new labor law (3rd ed.). Ibrahim AL nahel, Alexandria.

Fendi, M. (2015). the legal and factual justification for the termination of the will of individual contract according to the Labor Law, "compared to the Dar Al-Hamed for publication and distribution study, Amman. First Edition.

Grada, N. (2013). dependency on individual labor relations "comparative analysis", Master Thesis, Al-Azhar University, Gaza.

Hamdan, H. (2007). the Lebanese Labor Law "comparative study" (3rd ed.). publications Halabi rights, Beirut.

Hashim, H. (1990). explaining the Jordanian Labor Law (2nd ed.). Amman.

Jordanian Civil Code 43. 1976.

Jordanian Labor Law 8. 1996 and its amendments.

Jordanian Lawyer bar Journal. Edt. No. 9 \& 10 September / October 2002.

Judicial Journal / Judicial Institute of Jordan, First Issue Volume I, July 1997.

Justice Center magazines / Jordan.

Karam, A. W. (1998). labor law. the House of Culture for distribution and publishing, Amman.

Mabrouk, M. M. (2009). dependency within the scope of individual work, "an analytical study in labor law. The Egyptian and French relationship," Arab Renaissance Publishing House Cairo in 2009.

Magrby, J. (2016). explain the provisions of the labor law, the House of Culture for Publishing and Distribution Edition 1, Amman.

Malkawi, B. (2003). the principle of legality in the labor contract in the Jordanian Labor Law. Journal of Studies, $30(2)$.

Moneim, K. A. (2008). the individual employment contract (1st ed.). the National Center for versions of Cairo.

Otoum, M. (n.d.). explaining the Jordanian labor law, comparative study.

Qadir, A. A. (2011). sources of commitment. the House of Culture for Publishing and Distribution, Amman.

Ramadan, S. (2005). the mediator in the explanation of the Labor Law. the House of Culture for Publishing and Distribution, Amman.

Sanhouri, A. R. (n.d.). the mediator in the explanation of the new Civil Code, Part I, contracts set to work in 2000, Dar al-Halabi publication, Beirut.

Sarhan, A., \& al-Khater, N. (2005). explaining the Civil Code: sources of personal rights: Obligations (comparative study). the House of Culture for Publishing and Distribution, Amman.

Shanb, A. A. (1998). explained Jordan's new labor law (1st ed.).

The Holy Quran.

\section{Copyrights}

Copyright for this article is retained by the author(s), with first publication rights granted to the journal.

This is an open-access article distributed under the terms and conditions of the Creative Commons Attribution license (http://creativecommons.org/licenses/by/4.0/). 